\title{
Distal-Type Epithelioid Sarcoma
}

National Cancer Institute

\section{Source}

National Cancer Institute. Distal-Type Epithelioid Sarcoma. NCI Thesaurus. Code C27473.

An epithelioid sarcoma involving the extremities. It usually presents as nodular masses in the dermis and subcutaneous tissues or in the tendons and fascia. It frequently recurs and metastasizes to other anatomic sites. The most common sites of metastasis are the lungs, lymph nodes, bones, and brain. 